\title{
Religion and Desire for Additional Children in a Son- preference and Low Fertility Society: Evidence From Vietnam
}

Nguyen Thi Hai Yen

Chulalongkorn University College of Population Studies

Truc Ngoc Hoang Dang

Mahidol University Institute for Population and Social Research

Pataporn Sukontamarn (D pataporn@hotmail.com )

Chulalongkorn University https://orcid.org/0000-0003-4110-9697

\section{Research}

Keywords: Religion, fertility desire, desire for additional children, son preference, Vietnam

Posted Date: May 7th, 2021

DOI: https://doi.org/10.21203/rs.3.rs-466662/v1

License: (c) (i) This work is licensed under a Creative Commons Attribution 4.0 International License.

Read Full License 


\section{Evidence from Vietnam}

3 Plain English Summary

4 Aim of the research: This research aims to look into the association between religion and the

5 desire to have additional children of women in Vietnam. We focus on women of reproductive age $6 \quad(15-49$ years old $)$.

7 Background: Vietnam provides a unique case study. The country is known for son preference 8 and low fertility. The majority of Vietnamese people have no religion. The two main religions 9 in Vietnam are Buddhism and Christianity.

10 Data and methods: We use data from the 2014 Vietnam Multiple Indicator Cluster Survey. We 11 use statistical analysis to find out the relationship between religion and desire for additional 12 children among women of reproductive age. We conduct the study for overall Vietnam and for 13 each region, as there are large differences across regions.

14 Main findings: Religion has a strong relationship with the desire for additional children, and the 15 relationship differs across regions. In three out of six regions, Christians are more likely to want 16 another child compared to those with no religion. In Mekong River, Buddhists are less likely to 17 want another child compared to those with no religion. For Northern Midlands, however, 18 Buddhists are more likely to want another child compared to those with no religion. The study 19 also shows that son preference exists in all regions of Vietnam, with the level increasing from the 20 South towards the North.

21 Policy implications: Understanding the relationship between religion and desire for additional 22 children for each region can support the formulation of appropriate population policies for each 23 region in Vietnam. 


\section{Abstract}

Background: The association between religion and desire for additional children has remained controversial and varies depending on the social context of the study. This study 27 empirically investigates the relationship between religion and desire for additional children in 28 Vietnam, a society characterized by son preference and low fertility.

Methods: Using nationally representative data from the 2014 Vietnam Multiple Indicator Cluster Survey, the study employs Probit regression analysis to investigate the relationship 31 between religion and desire for additional children among women of reproductive age (15-49).

32 The sample consists of 5,585 women across all six economic regions. relationship differs across economic regions. In three out of six regions, Christians have higher fertility desire compared to non-religious people. Fertility desire of Buddhists differs from fertility desire of non-religious people in two out of six regions, namely Northern Midlands and Mekong

37 River. Fertility desire of those belonging to other religions is different from that of non-religious people only in Mekong River.

Conclusions: Identifying the impact of religion on desire for additional children can help promote appropriate family planning policies. The study also demonstrates that son preference exists in all regions of Vietnam, with the level increasing from the South, towards the Central and

42 peaks in the North, especially in the regions bordering China.

43 Key words: Religion, fertility desire, desire for additional children, son preference, Vietnam. 


\section{Introduction}

The world is facing a shift in fertility not only from high to low, as observed during the late 1950s to the late 1970s (1), but also unpredictable changes in fertility trends, especially prolonged

49 low fertility, new unions with lower demand for children, and voluntary childlessness (2). Besides,

50 due to the direct, indirect, and long-term effects brought about by changes in fertility trends, such

51 as population aging, economic consequences, and sex-imbalance due to son-preference, efforts to

52 intervene in fertility behavior are key policies for many countries (3).

The relationship between fertility desire and fertility is well documented (4). Fertility desire

54 is considered an important first step to achieve actual fertility (5). Thus, understanding fertility

55 desire will help policy makers to predict fertility and enable them to design appropriate policies

56 (6). There are many studies that have documented the determinants of fertility desire, including

57 economic conditions (7), health status (8), national population policy, socio-cultural context,

58 environmental impacts, and beliefs about values and benefits of children $(9,10)$. Religion is

59 reported to have a strong relationship with fertility desire as well as fertility in many countries (11,

60 12). For example, religious women tend to have higher fertility desire and higher fertility than

61 women without religion in the United States, Spain and most European countries (13).

Vietnam provides a unique case study, as the country has a special socio-political structure.

63 Under the Communist party's leadership, the majority of Vietnamese people follow the atheism

64 idea due to the policy set by the government (14). In addition, given the country's past experiences,

65 there are many different religions in Vietnam such as Confucianism, Cao Dai, Christianity, 66 Buddhism, etc. $(15,16)$. In addition, to the best of our knowledge, while there are a number of in-

67 depth studies on religions in Vietnam (17), so far there is no quantitative research to explore the 68 relationship between religion and demographic behaviors such as fertility desire. In addition, 
previous studies have shown that fertility desire in Vietnam is shaped by traditions and norms such

70 as son preference (10). As previous research has shown that fertility desire in Vietnam is

71 determined by socio-cultural ideology, this study hypothesizes that religion, a belief factor similar

72 to social culture, also determines fertility desire in Vietnam.

In sum, religion in Vietnam is likely to influence behaviors in many ways, but goes

74 unnoticed in formulating population policies. Moreover, there has been no previous work on the

75 impact of religion on fertility behavior in Vietnam. Therefore, this study is expected to be one of

76 the first studies in Vietnam to investigate the relationship between religion and fertility desire. We

77 aim to explore how religion influences fertility desire in a son-preference and low fertility society

78 dominated by atheism. Research results are expected to play an important role in the formulation

79 of population policies in Vietnam.

80

\section{Country context}

\section{Religion and culture belief in Vietnam}

Vietnam is recognized as a country with many religions, beliefs and socio-cultural traditions. For example, Buddhism was introduced to Vietnam very early and dominated the cultural and spiritual life from the first century to the 7th century, until the arrival of Confucianism from China (17). From the beginning of the $10^{\text {th }}$ century till present, Confucianism has mainly dominated the socio-cultural life and the behavior of Vietnamese people due to over a thousand years of Chinese domination (16). The Confucian morality stipulates that men must be the main breadwinner of the family who make decisions on important family matters and educate all family members (18). On the other hand, women's main role is to take care of the family. A woman is required to always obey her father when she is unmarried, her husband during marriage, and when 
92 the husband dies, listen to her eldest son (19). Confucianism promotes the idea of respecting men

93 because men take on the role of continuing the lineage and worshiping ancestors (20).

94 Confucianism places importance on having at least one son, as daughters are thought to belong to

95 their husbands' families after marriage (21).

Christianity in present-day Vietnam has two main branches which are Roman Catholic and

97 Protestant (22). Roman Catholic is considered the first of Christianity in Vietnam and was evangelized during the French colonial period, and Protestantism came to Vietnam around 1911 (23). By 2019, Catholics accounted for the highest percentage (6.1 percent) among the group of people with religion, while the proportion of Protestants was 1.0 percent (24). Unlike Buddhism, which does not clearly state the view of the value of children, both Catholic and Protestant Bibles 102 clearly state that children are gifts from God. Thus, Catholics and Protestants are expected to have 103 higher fertility desire compared to those not belonging to these two religious groups (25).

Since 1954, under the communist political regime, Vietnam has become an atheist state. At present, the proportion of people without religion is higher than the proportion of those with religion $(14,15)$. According to the 2019 population and housing census, the percentage of the population without religion accounts for 86.3 percent (24). In addition, Vietnam is also home to different religious groups such as Cao Dai, Hoa Hao Buddhism, Islam, and other religions that appeared in the early 20th century (17). As of 2009, each of these groups accounted for less than 1 percent of the population (24).

As a result, religions in Vietnam today are quite diverse due to the mixture of different 112 religious forms along with the development of the nation. Conceptions of each type of religion and 113 belief are also changed to suit people's beliefs (19). However, son preference still has a heavy 
114 influence on Vietnamese society, in parallel with the strong development of atheism according to

115 the communist ideals.

\section{Methods}

\section{Study Design}

This study draws on nationally representative data from the 2014 Vietnam Multiple

Indicator Cluster Survey (MICS). In-person interviews were conducted in six economic regions of

121 Vietnam, where the information was collected from reproductive-age women (15 to 49 years). The

1222014 MICS survey collected data from 10,018 households and 9,827 women residing in the

123 households. The information on the households and on the women were provided in two separate

124 datasets. In this study, we merged these separate datasets, using a unique identifier, to capture

125 information both at the household level and the individual level. Given that the main purpose of

126 this study is to investigate the association between religion and desire for additional children, we

127 restricted the dataset to women with at least one child. This produced a sample of 5,585 women

128 with at least one child.

\section{Measures}

Fertility desire: The dependent variable is fertility desire. This is captured by women's

131 desire to have additional child in the future at the time of interview. Women who had at least one

132 child were asked "Would you like to have (a/another) child, or would you prefer not to have any 133 more children?" $(0=$ no more, $1=$ have another child $)$. We excluded women who were not physically 134 able to get pregnant.

Religion: Religion is the main independent variable. We employ self-reported religion, 136 where the respondents reported their own religion. The question regarding religion in the 
137 household questionnaire has the following choice of answers: (1) Buddhism, (2) Islam, (3) Cao

138 Dai, (4) Hoa Hao, (5) Christianity (Catholicism), (6) Christianity (Protestantism), (7) Other

139 religion, (8) No religion. We grouped the responses into the following 4 categories: (1) No

140 religion, (2) Buddhism, (3) Christianity (including Catholicism and Protestantism), (4) Other

141 religions (including all the other religions).

$142 \quad$ Methodology

143 First, the test for perfect collinearity is conducted; the results indicate that all independent

144 variables do not have a high correlation with one another. For the descriptive statistics, the Fisher

145 exact test is applied instead of the Chi-squared test because the number of observations for specific

146 religions are small and does not satisfy the condition of sample size for Chi-squared test.

147 For the main analysis, ordered probit regression is employed to examine the relationship

148 between religion and desire for additional children and marginal effects are reported. The

149 estimated probability of desire for additional children comes from:

$$
F(Y=1 \mid X)=\Phi\left(X^{R C} \beta\right)
$$

Where $F$ denotes a fertility outcome (the probability that a woman wants to have additional 152 children), and $\Phi$ is the Cumulative Distribution Function (CDF) of the standard normal 153 distribution. Here $\beta$ is estimated by maximum likelihood. $X^{R C}$ is the set of independent variables 154 that are comprised of:

155 (i) Main independent variables: These are the variables representing religion of the 156 157 respondent. The information comes from self-reported religion which has 4 categories, namely, Buddhism, Christian, other religion and no religion. Here no religion is the baseline category. 
(ii) The control variables in the model include socio-demographic characteristics of the women (women's education, age at last birth, whether living in female-headed sex composition of children (i.e., having no son) to investigate how religion is associated with the

173 desire for additional children, conditional on the sex composition of children. according to religion and sex composition of living children, classified by region. The differences

177 in desire for additional children based on religion are statistically significant at the $5 \%$ level in 178 North Central and Central Highlands, and 10\% level in Northern midlands. For North Central, 179 women belonging to other religions have the highest percentage wanting additional children, while 180 Buddhists have the lowest percentage, followed by those with no religion. In the case of Central 181 Highlands, Christians have the highest percentage of women who wanted another child, while 
182 Buddhists have the lowest percentage. On the other hand, for Northern midlands, Buddhists have 183 the highest proportion of women who wanted to have additional children, followed by Christians, 184 and those with no religion, respectively. For South East, Red River, and Mekong River, the 185 differences are not statistically significant.

The percentage of women who wanted another child based on sex composition of living

187 children provides clear evidence of son preference across all regions of Vietnam. The percentage 188 of women with no son who wanted additional children is much higher than in the case of women 189 with at least one son. The differences are statistically significant at the $1 \%$ level for all six regions 190 of Vietnam.

\section{Empirical Findings}

Tables 2 and 3 present the relationship between religion and fertility desire. Table 2 reports

194 the results with the level terms only, while Table 3 additionally includes the interaction terms between dummy variables representing different religions and having at least one son.

The results in Table 2 suggest that son preference is prevalent across all regions of Vietnam.

197 The variable 'having at least one son' is negative and statistically significant for overall Vietnam 198 and all six regions. The results imply that women with at least one son are less likely to want 199 another child compared to women with no son. The magnitude of the marginal effect ranges from 200 smallest (-0.04) in South East and Mekong River, to largest (-0.15) in Northern Midlands. The 201 results suggest that the level of son preference is increasing from the South, to the Central, to the

202 North of Vietnam. The level of son preference appears strongest in the northernmost part of 203 Vietnam which borders China (namely Northern Midlands). The results also show that women 204 with more children are less likely to want another child, as expected. 
In the case of Buddhism, the results in Table 2 suggest that, for Northern Midlands, 206 Buddhists are more likely to want another child compared to those with no religion, controlling 207 for other factors. On the other hand, for Mekong River, Buddhists are less likely to desire 208 additional children compared to those with no religion. For all other regions and overall Vietnam, 209 the difference is not statistically significant. The results in Table 3 show that, for Northern 210 Midlands, the level term 'Buddhism' is positive and statistically significant, while the interaction 211 term between 'Buddhism' and 'having at least one son' is negative and statistically significant.

212 The level term result implies that, for women with no son, Buddhists are more likely to want 213 another child compared to those with no religion. The interaction term result suggests that, 214 conditioned on having at least one son, Buddhists are less likely to want another child compared 215 to women with no religion. The results together imply stronger son preference among Buddhists 216 as compared to those with no religion in Northern Midlands. For all other regions and overall 217 Vietnam, the level term 'Buddhism' and the interaction term between 'Buddhism' and 'having at 218 least one son' are not statistically significant.

For Christianity, the results in Table 2 demonstrate that, controlling for other factors, 220 Christians are more likely to want another child compared to women with no religion in the case 221 of South East, North Central, Central Highlands, and overall Vietnam. Table 3 shows that the 222 level term 'Christianity' is positive and statistically significant in the case of South East and overall 223 Vietnam. The results imply that, for those with no son, Christians are more likely to want another 224 child compared to women with no religion in the case of South East and overall Vietnam. The 225 interaction term between 'Christianity' and 'having at least one son' is negative and statistically 226 significant in the case of South East, and positive and statistically significant in the case of North 227 Central. For South East, conditioned on having at least one son, Christians are less likely to want 
228 another child compared to women with no religion. On the other hand, for North Central, 229 conditioned on having at least one son, Christians are more likely to want another child compared 230 to those with no religion.

231 For other religions, the results in Table 2 suggest that women belonging to other religions

232 are less likely to want another child compared to those with no religion in Mekong River. For all 233 other regions and overall Vietnam, the difference is not statistically significant. Table 3 presents 234 the results including the interaction term between 'Other religions' and 'having at least one son'. 235 In the case of Central Highlands and overall Vietnam, for those with no son, women belonging to 236 other religions are less likely to want another child compared to those with no religion. On the 237 other hand, in the case of North Central, for those with no son, women belonging to other religions 238 are more likely to want another child compared to those with no religion. Tables 2 and 3 show that several control variables are correlated with desire for additional 240 children. Education appears an important factor determining desire for additional children. For 241 overall Vietnam, women with lower secondary, upper secondary, and university education are 242 more likely to want another child compared to those with primary education or lower. The positive 243 relationship between education and desire for additional children is observed in South East and 244 Northern Midlands. On the other hand, women with higher education are less likely to want 245 another child compared to those with primary education or lower in the case of Red River. For 246 other regions, there is no statistically significant relationship between education and desire for 247 additional children. The relationship between income and desire for additional children also varies depending 249 on the region. For overall Vietnam, those belonging to the middle group are more likely to want 250 another child compared to the rich. For Red River and Mekong River, women who are poor are 
251 more likely to want another child compared to those who are rich. On the other hand, for South

252 East, women who are poor are less likely to want another child compared to those who are rich.

Several socio-demographic characteristics of the women, children's characteristics, and

254 social indicators are correlated with desire for additional children. For overall Vietnam as well as

255 all six regions, women whose last child is older are less likely to want additional children, as would

256 be expected. Moreover, women who were older when their last child was born are less likely to

257 desire additional children. For overall Vietnam and all six regions, compared to women who are

258 married, those who are widowed/divorced/separated are less likely to want additional children.

259 Women who are heads of households are less likely to want another child in the case of Red River.

260 For North Central, women who have experienced child mortality are more likely to want additional

261 children compared to those who do not have such an experience. Access to mass media is

262 positively correlated with desire for additional in the case of Northern Midlands. In the case of

263 overall Vietnam and Mekong River, women from provinces with higher sex ratio are more likely

264 to want another child compared to those from provinces with lower sex ratio. For region of

265 residence, compared to women in South East, those in North Central are more likely to want

266 another child, controlling for other factors.

267

268

\section{Discussion}

269

The results show that there is a significant relationship between religion and fertility desire

270 in Vietnam, and the relationship differs across economic regions. This can be explained by the

271 differences in the degree of son preference as well as the sectors of employment and economic

272 conditions across the regions. Christians have higher fertility desire compared to non-religious

273 people in three out of six regions, namely Southeast, North Central and Central Highland. Fertility 
274 desire of Buddhists differ from fertility desire of non-religious people in two out of six regions, 275 which are Northern Midlands and Mekong River. For those belonging to other religions, their 276 fertility desire is different from that of non-religious people only in Mekong River. Compared 277 with earlier studies which investigate the relationship between socio-cultural factors (in particular 278 son preference) and fertility desire $(26,27)$, this study adds to previous findings that spiritual 279 factor, namely religion, is also linked to fertility desire.

Another contribution of the study is the demonstration that son preference exists in all 281 regions of Vietnam, with the level increasing from the South, towards the Central and peaks in the 282 North, especially in the regions bordering China. This result is consistent with the research on 283 fertility desire of Vietnamese women (10), where son preference has been confirmed to exist in all 284 regions of Vietnam, and the level is higher in the North than in the South. Therefore, the study 285 provides support for more explicit intervention policy in eliminating traditional patrilineal systems, 286 son preference, and gender bias in Vietnam for more effective fertility control. Regarding Buddhism, the results show the difference in fertility desire between Buddhists 288 and those with no religion in Northern Midlands and Mekong River. In Northern Midlands, 289 Buddhists tend to want more children compared to those with no religion. On the other hand, in 290 Mekong River Buddhists are less likely to want another child compared to those with no religion. 291 The combination of the differences in the sectors of employment, the level of son preference and 292 economic status can provide reasonable explanations. The forestry land use in Northern Midlands 293 and Mountain areas was 6098.5 thousand hectares compared to 511.2 thousand hectares in Mekong 294 River (28). As a result, Northern Midland's main economic sector is based on forestry, so there is 295 more need for children to support the household economy. Also, as mentioned above, the level of 296 son preference is very high in Northern Midlands (Northern part of Vietnam) compared to Mekong 
297

298

299

300

301

302

303

304

305

306

307

308

309

310

River (Southern part of Vietnam). Moreover, in Northern Midlands, Buddhists are the poorest group in society, while in Mekong River Buddhists are among the richest. It is possible that, in Northern Midlands, Buddhist are more likely to want another child compared to those with no religion as they are poorer and likely to work in agriculture. As those with no religion in Northern Midlands are more likely to work for the government, their fertility desire is possibly affected by the one-or-two child policy. On the other hand, for the more economically developed Mekong River, Buddhists are among the richest groups in society and are more likely to work in the service sector such as trade. As Mekong River has low Total Fertility Rate (TFR), and Buddhists do not have specific religious value of children (as in the case of Christians), they are more likely to follow the social norms of lower fertility in the region. This possibly explains the lower fertility desire of Buddhists compared to those with no religion in the region. Previous studies have demonstrated the relationship between economic conditions and fertility both in developed and developing countries $(29,30)$. The results here show that, while religion is associated with fertility desire, economic conditions can shape the direction of the relationship.

Another interesting finding is that the Buddhists have stronger son preference than those without religion in the Northern Midlands. In Vietnam, non-religious people are likely the group that work in government agencies because non-religiousism is the direction of the communist regime (31). They also tend to have higher education which is required for government positions, and high educational attainment has been linked to low fertility in many studies $(32,33)$. Additionally, government workers have pension funds, so they do not need to financially depend on children during old age. High education and old age financial security can lead to low fertility desire among government workers. The one-or-two child policy also applies only to those employed by the government and members of the Communist Party. Therefore, non-religious 
320 people working for the government are also likely to limit their desire to have children. On the

321 other hand, Buddhists in Northern Midlands are poor and more likely to work in agriculture,

322 therefore having sons can be important for them as sons can help in agricultural work.

323 Regarding Christianity, Christians are more likely to want another child compared to

324 women with no religion. The difference in fertility desire can be influenced by the value of children

325 among Christians, where children are considered a gift from God. Therefore Christians are more

326 inclined to have children compared to non-religious people $(25,34)$. Additionally, both Christians

327 and Protestants refrain from using contraception because it is against the fundamental principle of

328 Roman Catholic marriage and against the Protestants' bible content "be fruitful and multiply" (35).

329 Besides, for those with no son, Christians are more likely to want another child compared to

330 women with no religion. As discussed above, non-religious people tend to work as government

331 officials, therefore the one-or-two-child policy can be an explanation here. On the other hand,

332 Christians are free to have more children until they have a son.

In addition, there are two conflicting trends in the fertility desire between Christians and

334 non-religious people who have at least one son in South East and Northern Midlands. For South

335 East, conditioned on having at least one son, Christians are less likely to want another child

336 compared to women with no religion. On the other hand, for Northern Midlands, conditioned on

337 having at least one son, Christians are more likely to want another child compared to those with

338 no religion. TFR in the South East has always been lower than TFR the Northern Midlands over

339 the past decade (28). Christians with at least one son in South East are perhaps more likely to

340 follow the social norm of low TFR in the region. For Northern Midland, it is possible that

341 Christians are more likely to follow the social norms of high TFR while those with no religion are

342 more likely to be constrained by the one-or-two child policy. Moreover, mix-gender preference is 
343 also confirmed in Northern Midland (10). Therefore, in the case of Christians (who are not 344 constrained by the one-or-two child policy), even if they already have one son, they might be more 345 likely to want another child in order to have children of both genders.

In the case of other religions, in Mekong River, women belonging to other religions are

347 less likely to want another child compared to those with no religion. Further analysis reveals that

348 there are differences in the level of education and economic status between those belonging to 349 other religions and those with no religion in Mekong River. People belonging to other religions 350 have lower education and economic status compared to non-religious people. It is possible that, in 351 certain context, those with low education and economic status have lower fertility desire compared 352 to those with high education and economic status. This result is in line with studies indicating that 353 higher education and income can lead to higher fertility due to the ability to bring up children (36). 354 It is also possible that the beliefs of women belonging to other religions influence their fertility 355 desire.

On the other hand, in Northern Midlands and Mountain Areas, for those with no son, 357 women belonging to other religions are more likely to want another child compared to those with 358 no religion. There are two plausible reasons for this. Firstly, we expect followers of other religions 359 to be from mountainous ethnic minorities, therefore, they have the opportunity and are allowed to 360 have many children according to the government's fertility incentive policy aimed at protecting 361 ethnic minorities. Secondly, as explained above, son preference and the need for a son to support 362 the family in the agricultural and forestry sector is quite high in the Northern Midlands. This is 363 possibly the case for those belonging to other religions as they are likely to work in agriculture.

\section{Conclusions}


Our research provides key findings on the relationship between religion and desire for 367 additional children in Vietnam, a society characterized by son preference and low fertility. 368 Religion has strong impact on desire to have an additional child, especially for women with low 369 economic status. Those who have a religion are more likely to want another child compared to 370 those with no religion. In Vietnam, government officials are constrained by the one-or-two child 371 policy and are also more likely to report having no religion (or are Buddhists rather than 372 Christians). This could partly explain the finding that those who reported having no religion are 373 less likely to want additional children compared to those having a religion (particularly Christians 374 and Buddhists). The findings also suggest strong son preference in Vietnam, with the highest level 375 in the Norther part bordering China. Preventing ultrasounds to detect fetal sex, sex-selective 376 abortion and improving women's empowerment have long term implication for reducing son 377 preference and improving women's health. This paper has identified the relationship between 378 religion and fertility desire, and the findings have implications for appropriate family planning 379 policies for a developing country as Vietnam.

\section{References}

382 1. Caldwell JC. The Globalization of Fertility Behavior. Demographic Transition Theory. 383 Dordrecht: Springer Netherlands; 2006. p. 249-71.

384 2. Tanturri ML, Mencarini L. Childless or Childfree? Paths to Voluntary Childlessness in Italy. 385 Population and Development Review. 2008;34(1):51-77.

386 3. Grant J, Hoorens S, Sivadasan S, van het Loo M, DaVanzo J, Hale L, et al. Low Fertility and 387 Population Ageing: Causes, Consequences, and Policy Options: RAND Corporation; 2004.

388 4. Thomson E, McDonald E, Bumpass LL. Fertility desires and fertility: Hers, his, and theirs. 389 Demography. 1990;27(4):579-88. 
390 5. Schoen R, Astone NM, Kim YJ, Nathanson CA, Fields JM. Do Fertility Intentions Affect

391 Fertility Behavior? Journal of Marriage and Family. 1999;61(3):790-9.

392 6. Hayford SR, Agadjanian V. From desires to behavior: Moderating factors in a fertility transition.

393 Demographic research. 2012;26:511-42.

$3947 . \quad$ Chen S-M, Zhang Y, Wang Y-B. Individual differences in relative fertility costs and fertility

395 benefits and their effects on fertility desire for a second child in China: a latent profile analysis.

396 Reproductive Health. 2019;16(1):110.

397 8. Tavousi M, Motlagh ME, Eslami M, Haerimehrizi A, Hashemi A, Montazeri A. Fertility desire 398 and its correlates: a pilot study among married citizens living in Tehran, Iran. Health Monitor Journal of 399 the Iranian Institute for Health Sciences Research. 2015;14(5):697-702.

400 9. Zhenzhen Z. Fertility Desire of Married Women in China [J]. Population Science of China. $401 \quad 2004 ; 5$.

402 10. Yen NTH, Sukontamarn P, Dang TNH. Sex-Composition of Living Children and Women's 403 Fertility Desire in Vietnam. Journal of Family \& Reproductive Health. 2020;14(4).

404 11. Borooah V, Iyer S. Religion and Fertility in India: The role of son preference and daughter 405 aversion. Cambridge Working Papers in Economics. 2004.

406 12. McQuillan K. When Does Religion Influence Fertility? Population and Development Review. $407 \quad 2004 ; 30(1): 25-56$.

408 13. Cranney S. The Association Between Belief in God and Fertility Desires in Slovenia and the 409 Czech Republic. Perspectives on Sexual and Reproductive Health. 2015;47(2):83-9.

410 14. Dang TNH. Direct and Indirect Impacts of Education on Subjective Well-being of Older Persons 411 in Vietnam: Gender Differences: Chulalongkorn University; 2018.

412 15. General Statistic Office. The 2009 Vietnam Population and Housing Census: Major Findings. Ha 413 Noi: Statistical Publisher; 2010. 
414 16. Huy NN. The Confucian incursion into Vietnam. In: Waler H. Stole and George A. De Vos, 415 editor. Confucianism and the Family. The United States of America: State University of New York Press, 416 Albany; 1998. p. 91-104.

417 17. Van Nghia H. Religious Diversity and the Right to Freedom of Religion in Vietnam Today2015.

418 18. Knodel J, Loi VM, Jayakody R, Huy VT. Gender roles in the family: Change and stability in 419 Vietnam. Asian Population Studies. 2005;1(1):69-92.

420 19. Grosse I. Gender Values in Vietnam - Between Confucianism, Communism, and Modernization.

421 The Institute for Peace and Unification Studies, Seoul National University; 2015. p. 253-72.

422 20. Vu TM, Yamada H. The legacy of Confucianism in gender inequality in Vietnam. Munich 423 Personal RePEc Archive. 2020.

424 21. Dang TNH, Sukontamarn P. Education and Subjective Well-Being among Older Vietnamese:

425 Exploring Gender Differences. Journal of Population and Social Studies [JPSS]. 2020;28(1):22-37.

426 22. Phan PC. Christianity in Vietnam today (1975-2013): contemporary challenges and

427 opportunities. International Journal for the Study of the Christian Church. 2014;14(1):3-21.

428 23. Vu TM, Yamada H. Sex Ratio and Religion in Vietnam. Munich Personal RePEc Archive. 2020.

429 24. General Statistic Office. The Vietnam Population and Housing Census of 00:00 Hours on 1 April

430 2019: Final Results [Kết quả Tổng Điều Tra Dân Số và Nhà Ở thời điểm 0 giờ ngày 01 tháng 4 năm

431 2019]. Central Population and Housing Census Steering Committee [Ban Chỉ Đạo Tổng Điều Tra Dân số

432 và Nhà ở Trung ương]; 2019.

433 25. Henderson CR. Christianity and Children. The Biblical World. 1896;8(6):473-82.

434 26. den Boer A, Hudson V. Patrilineality, Son Preference, and Sex Selection in South Korea and

435 Vietnam. Population and Development Review. 2017;43(1):119-47.

436 27. Guilmoto CZ. Son Preference, Sex Selection, and Kinship in Vietnam. Population and

437 Development Review. 2012;38(1):31-54.

438 28. General Statistic Office. Statistical YearBook of Vietnam 2014. Statistical Publishing House; 4392015. 
440 29. Bollen KA, Glanville JL, Stecklov G. Socio-economic status, permanent income, and fertility: A

441 latent-variable approach. Population Studies. 2007;61(1):15-34.

442 30. Dribe M, Breschi M, Gagnon A, Gauvreau D, Hanson HA, Maloney TN, et al. Socio-economic 443 status and fertility decline: Insights from historical transitions in Europe and North America. Population $444 \quad$ Studies. 2017;71(1):3-21.

445 31. Denney S. Religion and Dissent in Vietnam. Journal of Interdisciplinary Studies.

$446 \quad 2006 ; 18(1 / 2): 136-52$.

447 32. Monstad K, Propper C, Salvanes KG. Education and Fertility: Evidence from a Natural

448 Experiment*. The Scandinavian Journal of Economics. 2008;110(4):827-52.

449 33. Kravdal Ø. Education and fertility in sub-Saharan africa: Individual and community effects.

450 Demography. 2002;39(2):233-50.

451 34. Horn CB, Martens JW. " Let the little children come to me": childhood and children in early

452 Christianity: CUA Press; 2009.

453 35. Srikanthan A, Reid RL. Religious and Cultural Influences on Contraception. Journal of Obstetrics 454 and Gynaecology Canada. 2008;30(2):129-37.

455 36. Pedović I, Hedrih V. Do Educated People tend to have less Children? Fertility and Fertility 456 intentions across age and Gender in Sebia. Empirical Studies in Psychology. 2017:146.

457 


\section{Supplementary Files}

This is a list of supplementary files associated with this preprint. Click to download.

- Tables.pdf 